\title{
(2) OPEN ACCESS \\ Perinatal stabilisation of infants born with congenital diaphragmatic hernia: a review of current concepts
}

\author{
Emily J J Horn-Oudshoorn (D) , ${ }^{1}$ Ronny Knol, ${ }^{1}$ Arjan B Te Pas, ${ }^{2}$ Stuart B Hooper, ${ }^{3}$ \\ Suzan C M Cochius-den Otter, ${ }^{4}$ René M H Wijnen, ${ }^{4}$ Thomas Schaible, $^{5}$ \\ Irwin K M Reiss, ${ }^{1}$ Philip L J DeKoninck ${ }^{3,6}$
}

'Division of Neonatology, Department of Paediatrics, Erasmus MC University Medical Center, Rotterdam, The Netherlands

${ }^{2}$ Division of Neonatology, Department of Paediatrics, Leiden University Medical Center, Leiden, The Netherlands ${ }^{3}$ The Ritchie Centre, Hudson Institute for Medical Research, Monash University, Melbourne, Victoria, Australia

${ }^{4}$ Intensive Care and Department of Paediatric Surgery, Erasmus MC University Medical Center, Rotterdam, The Netherlands ${ }^{5}$ Department of Neonatology, University Children's Hospital Mannheim, University of Heidelberg, Mannheim, Germany

${ }^{6}$ Department of Obstetrics and Gynaecology, Erasmus MC University Medical Center, Rotterdam, The Netherlands

Correspondence to Philip L J DeKoninck, Department of Obstetrics and Gynaecology, Erasmus MC University Medical Center, PO Box 2060, 3000 CB Rotterdam, The Netherlands;

p.dekoninck@erasmusmc.nl

Received 26 November 2019 Revised 18 February 2020 Accepted 20 February 2020 Published Online First 13 March 2020

Check for updates

(C) Author(s) (or their employer(s)) 2020. Re-use permitted under CC BY. Published by BMJ.

To cite: Horn-Oudshoorn EJJ, Knol R, Te Pas AB, et al. Arch Dis Child Fetal Neonatal Ed 2020;105:F449-F454.

\begin{abstract}
Congenital diaphragmatic hernia (CDH) is associated with high mortality rates and significant pulmonary morbidity, mainly due to disrupted lung development related to herniation of abdominal organs into the chest. Pulmonary hypertension is a major contributor to both mortality and morbidity, however, treatment modalities are limited. Novel prenatal and postnatal interventions, such as fetal surgery and medical treatments, are currently under investigation. Until now, the perinatal stabilisation period immediately after birth has been relatively overlooked, although optimising support in these early stages may be vital in improving outcomes. Moreover, physiological parameters obtained from the perinatal stabilisation period could serve as early predictors of adverse outcomes, thereby facilitating both prevention and early treatment of these conditions. In this review, we focus on the perinatal stabilisation period by discussing the current delivery room guidelines in infants born with $\mathrm{CDH}$, the physiological changes occurring during the fetal-to-neonatal transition in $\mathrm{CDH}$, novel delivery room strategies and early predictors of adverse outcomes. The combination of improvements in the perinatal stabilisation period and early prediction of adverse outcomes may mitigate the need for specific postnatal management strategies.
\end{abstract}

\section{INTRODUCTION}

Congenital diaphragmatic hernia $(\mathrm{CDH})$ is a rare birth defect that affects around 1 in 2500 live births. ${ }^{1-3}$ Despite improvements in both prenatal and postnatal healthcare this condition is still associated with significant neonatal mortality, with rates varying between $30 \%$ and $50 \%$ and the majority of deaths occurring in the first year of life. ${ }^{13}$

The diaphragmatic defect can be surgically closed after birth, but the degree of disrupted lung development aggravated by herniation of abdominal organs into the chest determines survival. ${ }^{45}$ The resulting pulmonary hypoplasia is characterised by abnormal airways and vascular structures with increased smooth muscle deposition, leading to respiratory insufficiency and cardiovascular dysfunction after birth. ${ }^{45}$ The main consequence of this cardiovascular dysfunction is pulmonary hypertension $(\mathrm{PH})$, which results from underdevelopment of pulmonary vessels. ${ }^{6}$ Treating $\mathrm{PH}$ in $\mathrm{CDH}$ infants is challenging and severe $\mathrm{PH}$ at the age of 1 month is associated with a mortality rate of $56 \%$ at discharge. ${ }^{78}$ The incidence of $\mathrm{PH}$ in the first week of life was recently reported at almost 70\% in a cohort of nearly $3500 \mathrm{CDH}$ infants. ${ }^{9}$ Treating $\mathrm{PH}$-or preventing it-is accordingly a major target in $\mathrm{CDH}$ infants.

In recent decades, researchers have focused on developing antenatal interventions aimed at both improving pulmonary development by increasing the gas exchange area, as well as reducing $\mathrm{PH}$. The benefit of temporary tracheal occlusion using fetoscopy is currently evaluated in a randomised clinical trial(Tracheal Occlusion To Accelerate Lung Growth trial, NCT00763737/NCT01240057) and the results are expected this year. In preclinical research antenatal administration of vasodilator drugs, such as sildenafil, resulted in improved pulmonary vessel development; its efficacy is being investigated in a small clinical phase I/IIb trial. ${ }^{10}$ The efficacy of both surfactant and antenatal steroids has been evaluated in experimental and clinical trials, but these showed conflicting results for both therapies. Indeed, the apparent benefit in experimental trials could not be replicated in a clinical setting. ${ }^{11-20}$ Current postnatal protocols regarding treating $\mathrm{PH}$ in $\mathrm{CDH}$ are mostly based on trials performed in infants with persistent $\mathrm{PH}$ of the newborn. ${ }^{21}$ However, infants with $\mathrm{CDH}$ are often excluded from these studies and in fact most of these postnatal strategies do not seem effective in treating $\mathrm{PH}$ in $\mathrm{CDH}$, emphasising the necessity of developing novel approaches.

In this review, we will focus on the perinatal stabilisation period in the delivery room. We will summarise the available guidelines and discuss the known science on how the sequence of physiological changes is altered in infants with $\mathrm{CDH}$. In addition, we will provide an overview of novel delivery room strategies that aim to improve short and longterm outcomes as well as early predictors of adverse outcomes.

\section{DELIVERY ROOM MANAGEMENT: CURRENT GUIDELINES}

Current guidelines regarding the resuscitation of $\mathrm{CDH}$ infants are predominantly opinion based, since trials assessing delivery room management are lacking. Several large European centres published a consensus document, which was updated in 2015 (CDH EURO Consortium), and a similar guideline by the Canadian CDH Collaborative was published recently. $^{22} 23$ In contrast, the American Pediatric Surgical Association guideline does not provide recommendations regarding delivery room management in $\mathrm{CDH}$ infants. ${ }^{24}$ 

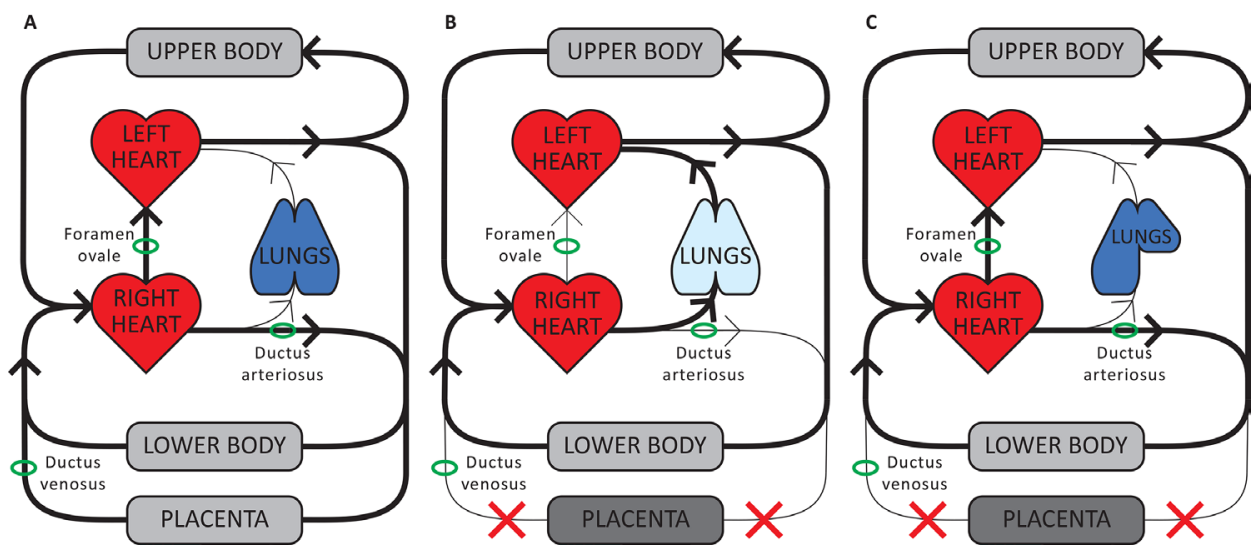

Figure 1 Cardiopulmonary physiology. (A) Fetal phenotype: left ventricular (LV) preload is mainly derived from umbilical venous blood which flows via the ductus venosus and foramen ovale directly into the left atrium. As pulmonary vascular resistance (PVR) is high, pulmonary blood flow (PBF) is low and the majority of right ventricular output bypasses the lungs and flows through the ductus arteriosus into the descending aorta. A high proportion of cardiac output flows through the low-resistance placental vascular bed, which contributes to a low-systemic vascular resistance (afterload). (B) Fetal-to-neonatal transition in healthy infants: umbilical cord clamping decreases LV preload and increases systemic vascular resistance by removing both umbilical venous return and the low-resistance placental vascular bed. Lung aeration triggers a decrease in PVR and an increase in PBF, which then re-establishes LV preload lost upon cord clamping. The lungs then take over both the cardiovascular and respiratory functions of the placenta. (C) Fetal-to-neonatal transition in infants with congenital diaphragmatic hernia: as airway liquid clearance is delayed, the decrease in PVR and increase in PBF are also delayed. As such, clamping of the umbilical cord immediately after birth results in a prolonged period of reduced cardiac output due to a loss in preload. As cardiac output is critical for defending the infant against hypoxia, a prolonged period of low cardiac output combined with limited or no oxygen exchange greatly increases the risk of hypoxic/ischaemic brain injury.

In both the European and Canadian guidelines, the key principle of stabilisation is to establish adequate perfusion and oxygenation while avoiding high airway pressures. ${ }^{22}$ Accordingly, most infants are intubated immediately after birth. However, in cases that are predicted to have good lung development based on prenatal assessment, a trial of spontaneous breathing could be considered according to the European guideline. ${ }^{22}$ The necessity of immediate support translates into immediate cord clamping (ICC) yet both guidelines do not dictate the exact timing of cord clamping. ${ }^{22}{ }^{23}$ Moreover, for all recommendations the level of evidence was graded as very low. This emphasises the necessity of generating robust scientific evidence that supports these treatment strategies.

\section{TRANSITION PERIOD}

\section{Fetal phenotype}

In the fetal circulation (figure 1A), left ventricular (LV) preload is mainly derived from umbilical venous blood flow that is preferentially streamed to the left atrium via the ductus venosus and the right-to-left shunt through the foramen ovale. ${ }^{2526}$ The placental circulation provides oxygenation of fetal blood, and greatly reduces overall systemic vascular resistance because placental vascular resistance is low. ${ }^{25}$ Pulmonary vascular resistance (PVR) is high since the fetal lungs are not aerated and as a result pulmonary blood flow (PBF) is low. Thus, the majority of the right ventricular output shunts from right to left through the ductus arteriosus to enter the systemic circulation. ${ }^{25}$

\section{Transition to neonatal phenotype in healthy newborns}

At the time of cord clamping several adaptations in the cardiovascular and pulmonary system occur as the low resistance placental vascular bed is removed from the systemic circulation (figure 1B). The loss of umbilical venous return decreases LV preload by $30 \%-50 \%$ and, when combined with an instantaneous increase in systemic vascular resistance, cord clamping results in a decrease in cardiac output as reflected by lower stroke volume and heart rate. ${ }^{25} 26$ This likely explains the observed transient bradycardia in the heart rate nomograms of normal healthy infants. ${ }^{27}{ }^{28}$ Lung aeration triggers the transformation of the fetal circulation into the neonatal phenotype by stimulating a decrease in PVR and an increase in PBF, which then re-establishes the preload lost on cord clamping. ${ }^{25}$ In healthy newborns, lung aeration is established rapidly after birth thereby avoiding severe hypoxia. ${ }^{5}$

\section{Transition to neonatal phenotype in $\mathrm{CDH}$}

For almost all infants born with $\mathrm{CDH}$, transition to the neonatal phenotype is complicated and support from medical professionals is essential for survival. However, our knowledge of how pulmonary hypoplasia affects the cardiopulmonary physiological changes during the transition period is largely based on animal models.

Hypoplastic lungs have low compliance, resulting in delayed lung aeration after birth (figure 1C). ${ }^{29}$ In particular, airway liquid clearance will be impeded because of an increased resistance to liquid flow down through the airways due to their smaller total cross-sectional area, in combination with a reduced surface area for liquid movement into the perialveolar tissue. ${ }^{29}$ Since lung aeration is the most important trigger for decreasing PVR and augmenting PBF, impaired airway liquid clearance and thus delayed lung aeration results in a delay in the sequence of physiological changes that transform the fetal circulation into a neonatal circuit. ${ }^{52530}$ Accordingly, after cord clamping there is a prolonged period of reduced cardiac output, resulting in gradually worsening of hypoxia and blood pressure fluctuations in the pulmonary and systemic vasculature.

Postnatal LV dysfunction-both systolic and diastolic-adds to the haemodynamic instability during transition in these $\mathrm{CDH}$ infants. $^{3132}$ The aetiology of LV dysfunction in CDH is multifactorial and is related to the relatively small size, resulting from both the herniation of abdominal organs as well as the altered LV filling haemodynamics. ${ }^{32} 33$ After cord clamping, LV dysfunction 
most likely results from reduced LV filling due to the limited increase in PBF (eg, preload), LV hypoplasia and acute increase in afterload. Moreover, there is transmission of right ventricular dysfunction to the $L V$ via ventricular interdependence. ${ }^{31} 32$

In an ovine diaphragmatic hernia $(\mathrm{DH})$ model, the lambs developed respiratory acidosis and poor cerebral oxygenation immediately after birth, confirming the hypothesised worsening of hypoxia after ICC. ${ }^{30}$ Hypoxia may result in an enhanced vasoconstrictive response since the pulmonary vasculature in $\mathrm{CDH}$ infants is hyper-reactive. ${ }^{30}$ The resulting increase in vascular resistance could worsen $\mathrm{PH}$, ultimately leading to an increase in the pre-existing right-to-left shunt, which in turn would aggravate the hypoxia and trigger an ongoing cycle of worsening $\mathrm{PH}^{583034}$

\section{DELIVERY ROOM MANAGEMENT: NOVEL CONCEPTS}

Improving outcomes of infants born with $\mathrm{CDH}$ requires clinical trials assessing innovative strategies in these infants. Considering it is a rare condition, large trials may not always be feasible as recruitment is not sufficient to achieve statistical and clinical significance within a reasonable time frame. This is also reflected by the fact that all concepts described in this paragraph have a low grade of recommendation (D). We will discuss early predictors of adverse outcomes and innovative treatment strategies during the perinatal stabilisation period that seem promising based on preclinical studies.

\section{Early prediction of adverse outcomes}

Several early prediction models and parameters during the immediate postnatal period have been suggested, which could allow initiation of prophylactic therapies in an attempt to individualise healthcare for each neonate. Herein we will discuss two parameters and three prediction models.

\section{Tidal volume}

In a prospective study, tidal volume $(\mathrm{Vt})$ of spontaneous breaths during stabilisation was associated with mortality, chronic lung disease incidence and the need for inhaled nitric oxide. ${ }^{35}$ However, Vt was correlated with the observed to expected lungto-head ratio (o/e LHR) and was therefore not considered an independent predictor. ${ }^{35}$ Still, it may be useful in confirming disease severity at birth. ${ }^{35}$

\section{Oxygenation index}

The oxygenation index (OI), a value calculated to estimate the severity of respiratory failure, may predict mortality in $\mathrm{CDH}$ infants. ${ }^{36} 37$ The highest OI recorded in the first 48 hours was positively associated with higher mortality, greater length of stay and more ventilator days in a retrospective study. ${ }^{37} \mathrm{~A}$ subsequent retrospective study confirmed that reported mean and best OI on day 1 were reliable predictors for mortality. ${ }^{36}$ Calculating the OI requires the arterial $\mathrm{PO}_{2}$ value, which is obtained by means of arterial blood gas sampling. However, as most $\mathrm{CDH}$ infants have a patent ductus arteriosus at this time and preductal $\mathrm{PaO}_{2}$ values are thus higher than postductal $\mathrm{PaO}_{2}$ values, the site of blood gas sampling could result in a major difference in the calculated OI. ${ }^{31}$ Moreover, arterial blood gas sampling is invasive, requiring an arterial line or intermittent arterial puncture. ${ }^{38}$ The use of the oxygenation saturation index, a non-invasive measure, can potentially alleviate these disadvantages of OI, although its use and usefulness in $\mathrm{CDH}$ infants has not been established. ${ }^{38}$

\section{Score for Neonatal Acute Physiology-II}

The Score for Neonatal Acute Physiology-II (SNAP-II Score) was first created in 2001 and is calculated with the use of arterial blood pressure, $\mathrm{pH}, \mathrm{PaO}_{2}: \mathrm{FiO}_{2}$ ratio, body temperature, diuresis and seizure activity. ${ }^{39} \mathrm{~A}$ prospective trial assessing the initial ventilation strategy in $\mathrm{CDH}$ infants showed the predictive value of SNAP-II for both mortality as well as the need for extracorporeal membrane oxygenation (ECMO) ${ }^{40}$ The SNAP-II Score is easy to use and its potential as early predictor was also confirmed in a more recent retrospective study. ${ }^{41}$

\section{Wilford Hall/Santa Rosa prediction model}

The Wilford Hall/Santa Rosa prediction formula was developed as an easy-to-use clinical method for predicting outcomes in the first 24 hours after birth. ${ }^{42}$ This formula is calculated by $\mathrm{PaO}_{2}[\max ]-\mathrm{PaCO}_{2}[\max ]$ and the authors hypothesised that in $\mathrm{CDH}$ infants with severe $\mathrm{PH}$, arterial $\mathrm{PO}_{2}$ would be less than $\mathrm{PCO}_{2}$ as result of compromised gas exchange. However, the clinical accuracy of this model was not sufficient in predicting outcomes of individual patients, and a subsequent clinical trial reported poor discrimination in predicting outcomes as well. ${ }^{42} 43$

\section{Brindle scoring model}

Brindle et al developed a third clinical prediction model in $2014 .{ }^{44}$ This model provides a simple and generalisable scoring system discriminating between low $(<10 \%)$, intermediate $(\sim 20 \%)$ and high $(\sim 50 \%)$ risks of mortality. ${ }^{44}$ This $\mathrm{CDH}$ scoring equation includes five predictors: 5 min Apgar, birth weight, $\mathrm{PH}$, chromosomal anomalies and major cardiac defects. ${ }^{44}$ External validation has confirmed good performance and discrimination among the three groups. ${ }^{45}$

\section{Ex utero intrapartum treatment-to-ECMO procedure}

Many of the severely affected $\mathrm{CDH}$ infants are treated with ECMO, although its efficacy in CDH remains debatable. The apparent small gain in survival rates may be offset by increased long-term disability in survivors. ${ }^{46} \mathrm{~A}$ potential explanation for this increased morbidity is that ECMO treatment is usually only considered when infants are already critically ill. In an attempt to improve the benefits of ECMO, the ex utero intrapartum treatment-to-ECMO (EXIT-to-ECMO) procedure was suggested for the patients with most severe CDH $(<15 \%$ predicted lung volume). ${ }^{4748}$ The first report demonstrated no clear survival benefit of EXIT-to-ECMO: mortality was higher than in the non-EXIT group. ${ }^{48}$ On the other hand, there was a higher incidence of cardiac anomalies in the EXIT-to-ECMO group. ${ }^{48} \mathrm{~A}$ second pilot series by the same group evaluated the potential benefit on morbidity outcomes. ${ }^{47}$ While the limited sample size (eight EXIT-to-ECMO vs nine non-EXIT) precludes firm conclusions from being drawn, there are some indications suggesting that survivors of the EXIT-to-ECMO treatment were healthier. ${ }^{47}$ The authors, however, conclude that based on their experience, which is the largest to date, the use of EXIT-to-ECMO for severe CDH infants has not resulted in improved outcomes. ${ }^{4748}$

\section{Initial respiratory support}

Respiratory support is a major topic in delivery room management for CDH infants, however, it is a double-edged sword as the importance of ventilator-induced lung injury (VILI) and oxygen toxicity is not to be underestimated. 'Gentle ventilation strategies' and permissive hypercapnia have been implemented in delivery room management and on intensive care 
units, as less aggressive ventilator strategies could reduce the risk of VILI and oxygen toxicity. ${ }^{22}$ However, the optimal way of guiding oxygen supplementation in CDH infants is still not clear. The possibility of causing inadvertent cerebral hyperoxia was highlighted in a recent study using an ovine DH model..$^{5}$ The authors hypothesised that this occurs when the $\mathrm{FiO}_{2}$ levels are rapidly increased in response to reduced $\mathrm{SpO}_{2}$ levels without knowledge of cerebral blood flows, leading to a rapid increase in cerebral oxygen delivery. ${ }^{5}$ To directly assess cerebral oxygenation, they have speculated that ventilation management may be better guided by the use of near-infrared spectroscopy. ${ }^{5}$

The CDH EURO Consortium also recommends that CDH infants may benefit from starting with $\mathrm{FiO}_{2}$ lower than 1.0. ${ }^{22}$ While there is minimal evidence to support this recommendation, reduced generation of free radicals associated with lower $\mathrm{FiO}_{2}$ levels may prevent subsequent pulmonary vasoconstriction. ${ }^{49}$ In a retrospective cohort series that compared starting resuscitation of $\mathrm{CDH}$ infants with $\mathrm{FiO}_{2} 0.5$ vs 1.0 (68 vs 45 patients), no differences in immediate postnatal outcomes were found. ${ }^{50}$ However, infants who required an increase in $\mathrm{FiO}_{2}$ during stabilisation were more likely to have an adverse outcome..$^{50}$

In infants predicted to have mild hypoplasia that are potentially capable of a smooth transition into neonatal life, the initiation of invasive respiratory support may actually cause damage to the lungs. To avoid VILI for this specific groupinfants with a left-sided defect, intra-abdominal liver and o/e LHR $\geq 50 \%$, a trial of spontaneous breathing was postulated in the consensus CDH EURO Consortium guideline. ${ }^{51}$ The benefit of such an approach has not been determined objectively, yet this has been explored in the Erasmus MC and a manuscript reporting our experience over a 5 -year period is currently under review.

\section{Timing of cord clamping}

The importance of appropriate timing of cord clamping in optimising perinatal stabilisation of newborns has been evaluated comprehensively over the last decade. ${ }^{25253}$ Delayed cord clamping (DCC) can be performed using either a 'time-based' or a 'physiological-based' approach, with the latter focusing on the infant and its physiological stability rather than a stopwatch. Indeed, the high variability between newborns in their needs and outcomes already suggests that DCC at an arbitrarily chosen point of time may not be sufficient. ${ }^{25}$ Initially, the benefits of DCC were attributed to an increase in placental transfusion, reducing the incidence of neonatal anaemia in both term and preterm infants. In preterm infants, however, the benefit of DCC may be more related to establishing lung aeration prior to cord clamping, resulting in a smooth cardiopulmonary adaptation at birth. ${ }^{26}$

In physiological-based cord clamping (PBCC), the umbilical cord is clamped after the infant has established lung aeration with spontaneous breathing or respiratory support. ${ }^{53} 54$ Lung aeration before cord clamping allows the pulmonary vasculature to dilate and PBF to increase, while maintaining LV preload through umbilical venous return. ${ }^{5455}$ Thus, an elevated PBF can immediately take over the maintenance of LV preload as soon as the cord is clamped, allowing the preservation of LV filling and function throughout the transitionary period. ${ }^{31}$ This would lead to a better cardiopulmonary transition compared with ICC, with prevention of hypoxia and loss of LV output. This concept has recently been confirmed in an ovine model, in which cardiopulmonary transition in DH lambs was compared between ICC and PBCC. ${ }^{530}$ In this experiment, $\mathrm{PBCC}$ translated into an increase in $\mathrm{PaO}_{2}$ and preductal $\mathrm{SaO}_{2}$, an almost 20 -fold greater $\mathrm{PBF}$ at the time of cord clamping $(\mathrm{p}<0.001)$, and a significantly lower pulmonary artery pressure at $10 \mathrm{~min}$ after ventilation onset $(\mathrm{p}<0.001) .^{30}$ $\mathrm{PBCC}$ in patients with $\mathrm{CDH}$ could also offer the opportunity of commencing resuscitation with $21 \%-50 \%$ instead of $100 \%$ of oxygen since the infants are still on the placental circulation and therefore require less supplemental oxygen. ${ }^{4956}$

As mentioned before, due to the hyper-reactive pulmonary vasculature in $\mathrm{CDH}$ infants temporary $\mathrm{PH}$ could lead to a cascade ultimately resulting in persistent PH. ${ }^{583034}$ Incorporating PBCC into the stabilisation of $\mathrm{CDH}$ infants could theoretically reduce the risk of ongoing $\mathrm{PH}$ in these infants simply by incorporating a low-risk intervention. If proven effective in humans, this could lead to a significant shift in delivery room strategies. The feasibility of intact cord resuscitation in $\mathrm{CDH}$ infants was recently demonstrated in two single-centre pilot studies; both studies did not observe maternal or neonatal adverse events with DCC. ${ }^{257}$ These trials were not designed to detect the impact of the intervention on the cardiopulmonary outcomes, although it was suggested that DCC improved early cardiorespiratory adaptation at birth. ${ }^{2}$ However, Foglia et al performed cord clamping after colorimetric carbon dioxide detection and as such, it is likely that cord clamping was performed without the infants being 'stabilised'.

Based on the promising preliminary results we will initiate a multicentre and international randomised controlled trial evaluating $\mathrm{PBCC}$ in $\mathrm{CDH}$ infants, the PinC trial (NL69575.078.19), starting in 2020. Left-sided CDH infants will be randomised to either standard approach (ie, ICC) or PBCC, meaning the umbilical cord will not be clamped until after the infant is stabilised. A consistent definition for physiological stability has not been established yet, but the goal is to assess adequate lung aeration. We decided to use physiological parameters as heart rate and oxygenation as proxy for aeration, because of its simplicity and is analogous to what is currently used in a trial evaluating the outcomes of PBCC in very preterm neonates. ${ }^{58}$ The PinC trial is designed to detect the impact of PBCC on clinical outcomes, for example, the occurrence of $\mathrm{PH}$ diagnosed in the first 24 hours after birth. In parallel, there are other ongoing and anticipated initiatives evaluating intact cord resuscitation in $\mathrm{CDH}$ infants in Denver (CO, USA) and France (nationwide), respectively.

\section{SUMMARY}

Infants with $\mathrm{CDH}$ will face important respiratory challenges immediately after birth and in some patients, deterioration of their clinical situation may be the result of our current management strategies at birth. We propose that this earliest time period of newborn life has the potential to provide both reliable markers for prediction of outcomes, such as $\mathrm{PH}$, and the possibility to adopt innovative management strategies in an attempt to have more children survive. Optimising perinatal stabilisation could protect hypoplastic lungs from damage due to the treatments that we employ to save their lives.

Twitter Arjan B Te Pas @None

Contributors EJJHO wrote the initial draft of the manuscript. All authors participated in critical revision of the manuscript. EJJHO and PLJD processed the remarks and accounted for the final version of the manuscript. All authors approved the final manuscript as submitted and agreed to be accountable for all aspects of the work. 
Funding EJJHO and PLJD are supported by a grant from Sophia Children's Hospital Foundation (SSWO, grant S19-12).

Competing interests ABTP and SBH are members of the advisory committee of Concord Neonatal; however, the authors declare that Concord Neonatal had no influence on the contents of this paper.

Patient consent for publication Not required.

Provenance and peer review Not commissioned; externally peer reviewed.

Data availability statement Data sharing is not applicable as no data sets were generated and/or analysed for this study.

Open access This is an open access article distributed in accordance with the Creative Commons Attribution 4.0 Unported (CC BY 4.0) license, which permits others to copy, redistribute, remix, transform and build upon this work for any purpose, provided the original work is properly cited, a link to the licence is given, and indication of whether changes were made. See: https://creativecommons.org/ licenses/by/4.0/

\section{ORCID iD}

Emily J J Horn-Oudshoorn http://orcid.org/0000-0002-0582-1129

\section{REFERENCES}

1 Lally KP. Congenital diaphragmatic hernia - the past 25 (or so) years. J Pediatr Surg 2016;51:695-8.

2 Lefebvre C, Rakza T, Weslinck N, et al. Feasibility and safety of intact cord resuscitation in newborn infants with congenital diaphragmatic hernia (CDH). Resuscitation 2017;120:20-5.

3 Leeuwen L, Fitzgerald DA. Congenital diaphragmatic hernia. J Paediatr Child Health 2014:50:667-73.

4 Chiu P, Hedrick HL. Postnatal management and long-term outcome for survivors with congenital diaphragmatic hernia. Prenat Diagn 2008;28:592-603.

5 Kashyap AJ, Crossley KJ, DeKoninck PLJ, et al. Neonatal cardiopulmonary transition in an ovine model of congenital diaphragmatic hernia. Arch Dis Child Fetal Neonatal Ed 2019;104:F617-23.

6 Montalva L, Antounians L, Zani A. Pulmonary hypertension secondary to congenital diaphragmatic hernia: factors and pathways involved in pulmonary vascular remodeling. Pediatr Res 2019;85:754-68

7 Wynn J, Krishnan U, Aspelund G, et al. Outcomes of congenital diaphragmatic hernia in the modern era of management. J Pediatr 2013;163:114-9.

8 McHoney M. Congenital diaphragmatic hernia, management in the newborn. Pediatr Surg Int 2015;31:1005-13.

9 Putnam LR, Tsao K, Morini F, et al. Evaluation of variability in inhaled nitric oxide use and pulmonary hypertension in patients with congenital diaphragmatic hernia. JAMA Pediatr 2016:170:1188-94

10 Russo FM, Benachi A, Van Mieghem T, et al. Antenatal sildenafil administration to prevent pulmonary hypertension in congenital diaphragmatic hernia (SToP-PH): study protocol for a phase I/llb placenta transfer and safety study. Trials 2018;19:524.

11 Morini F, Lally KP, Lally PA, et al. Treatment strategies for congenital diaphragmatic hernia: change sometimes comes bearing gifts. Front Pediatr 2017:5:195

12 Brandsma AE, Tibboel D, Vulto IM, et al. Ultrastructural features of alveolar epithelial cells in the late fetal pulmonary acinus: a comparison between normal and hypoplastic lungs using a rat model of pulmonary hypoplasia and congenital diaphragmatic hernia. Microsc Res Tech 1993;26:389-99.

13 Finer NN, Tierney A, Etches PC, et al. Congenital diaphragmatic hernia: developing a protocolized approach. J Pediatr Surg 1998:33:1331-7.

14 Lally KP, Bagolan P, Hosie S, et al. Corticosteroids for fetuses with congenital diaphragmatic hernia: can we show benefit? J Pediatr Surg 2006:41:668-74. discussion 68-74.

15 Lally KP, Lally PA, Langham MR, et al. Surfactant does not improve survival rate in preterm infants with congenital diaphragmatic hernia. J Pediatr Surg 2004;39:829-33.

16 Schnitzer JJ, Hedrick HL, Pacheco BA, et al. Prenatal glucocorticoid therapy reverses pulmonary immaturity in congenital diaphragmatic hernia in fetal sheep. Ann Surg 1996:224:430-9. discussion 37-9.

17 Somaschini M, Locatelli G, Salvoni L, et al. Impact of new treatments for respiratory failure on outcome of infants with congenital diaphragmatic hernia. Eur J Pediatr 1999;158:780-4.

18 Suen HC, Bloch KD, Donahoe PK. Antenatal glucocorticoid corrects pulmonary immaturity in experimentally induced congenital diaphragmatic hernia in rats. Pediatr Res 1994;35:523-9.

19 Van Meurs K, Congenital Diaphragmatic Hernia Study Group. Is surfactant therapy beneficial in the treatment of the term newborn infant with congenital diaphragmatic hernia? J Pediatr 2004;145:312-6.

20 van Tuyl M, Blommaart PE, Keijzer R, et al. Pulmonary surfactant protein A, B, and C mRNA and protein expression in the nitrofen-induced congenital diaphragmatic hernia rat model. Pediatr Res 2003;54:641-52.
21 Kraemer U, Cochius-den Otter S, Snoek KG, et al. Pharmacodynamic considerations in the treatment of pulmonary hypertension in infants: challenges and future perspectives. Expert Opin Drug Metab Toxicol 2016;12:1-19.

22 Snoek KG, Reiss IKM, Greenough A, et al. Standardized Postnatal Management of Infants with Congenital Diaphragmatic Hernia in Europe: The CDH EURO Consortium Consensus - 2015 Update. Neonatology 2016;110:66-74.

23 Puligandla $\mathrm{P}$, Skarsgard E, Offringa M, et al. Diagnosis and management of congenita diaphragmatic hernia: a clinical practice guideline. CMAJ 2018;190:E103-12.

24 Abman SH, Hansmann G, Archer SL, et al. Pediatric pulmonary hypertension: guidelines from the American heart association and American thoracic Society. Circulation 2015;132:2037-99.

25 Hooper SB, Polglase GR, te Pas AB. A physiological approach to the timing of umbilical cord clamping at birth. Arch Dis Child Fetal Neonatal Ed 2015;100:F355-60.

26 Hooper SB, Binder-Heschl C, Polglase GR, et al. The timing of umbilical cord clamping at birth: physiological considerations. Matern Health Neonatol Perinatol 2016:2:4.

27 Dawson J, Kamlin C, Wong C, et al. Changes in heart rate in the first minutes after birth. Arch Dis Child Fetal Neonatal Ed 2010;95:F177-81.

28 Polglase GR, Dawson JA, Kluckow M, et al. Ventilation onset prior to umbilical cord clamping (physiological-based cord clamping) improves systemic and cerebral oxygenation in preterm lambs. PLoS One 2015;10:e0117504

29 Flemmer AW, Thio M, Wallace MJ, et al. Lung hypoplasia in newborn rabbits with a diaphragmatic hernia affects pulmonary ventilation but not perfusion. Pediatr Res 2017;82:536-43.

30 Kashyap AJ, Hodges RJ, Thio M, et al. Physiologically based cord clamping improves cardiopulmonary haemodynamics in lambs with a diaphragmatic hernia. Arch Dis Child Fetal Neonatal Ed 2020;105:18-25.

31 Patel N, Massolo AC, Paria A, et al. Early postnatal ventricular dysfunction is associated with disease severity in patients with congenital diaphragmatic hernia. $J$ Pediatr 2018;203:400-7.

32 Gien J, Kinsella JP. Management of pulmonary hypertension in infants with congenital diaphragmatic hernia. J Perinatol 2016;36:S28-31.

33 Tingay DG, Kinsella JP. Heart of the matter? Early ventricular dysfunction in congenital diaphragmatic hernia. Am J Respir Crit Care Med 2019:200:1462-4.

34 Deprest JA, Gratacos E, Nicolaides K, et al. Changing perspectives on the perinatal management of isolated congenital diaphragmatic hernia in Europe. Clin Perinatol 2009;36:329-47.

51 Mank A, Carrasco Carrasco C, Thio M, et al. Tidal volumes at birth as predictor for adverse outcome in congenital diaphragmatic hernia. Arch Dis Child Fetal Neonatal Ed 2020;105:F248-52.

36 Tan Y-W, Ali K, Andradi G, et al. Prognostic value of the oxygenation index to predict survival and timing of surgery in infants with congenital diaphragmatic hernia. J Pediatr Surg 2019;54:1567-72

37 Bruns AS, Lau PE, Dhillon GS, et al. Predictive value of oxygenation index for outcomes in left-sided congenital diaphragmatic hernia. J Pediatr Surg 2018;53:1675-80

38 Rawat M, Chandrasekharan PK, Williams A, et al. Oxygen saturation index and severity of hypoxic respiratory failure. Neonatology 2015;107:161-6.

39 Richardson DK, Corcoran JD, Escobar GJ, et al. SNAP-II and SNAPPE-II: simplified newborn illness severity and mortality risk scores. J Pediatr 2001;138:92-100.

40 Snoek KG, Capolupo I, Morini F, et al. Score for neonatal acute Physiology-II predicts outcome in congenital diaphragmatic hernia Patients*. Pediatric Critical Care Medicine 2016:17:540-6.

41 Kipfmueller F, Schroeder L, Melaku T, et al. Prediction of ECMO and mortality in neonates with congenital diaphragmatic hernia using the SNAP-II score. Klin Padiatr 2019:231:297-303.

42 Schultz CM, DiGeronimo RJ, Yoder BA, et al. Congenital diaphragmatic hernia: a simplified postnatal predictor of outcome. J Pediatr Surg 2007:42:510-6.

43 Baird R, MacNab YC, Skarsgard ED, et al. Mortality prediction in congenita diaphragmatic hernia. J Pediatr Surg 2008:43:783-7.

44 Brindle ME, Cook EF, Tibboel D, et al. A clinical prediction rule for the severity of congenital diaphragmatic hernias in newborns. Pediatrics 2014;134:e413-9.

45 Bent DP, Nelson J, Kent DM, et al. Population-Based validation of a clinical prediction model for congenital diaphragmatic hernias. J Pediatr 2018;201:160-5.

46 Grover TR, Rintoul NE, Hedrick HL. Extracorporeal membrane oxygenation in infants with congenital diaphragmatic hernia. Semin Perinatol 2018;42:96-103.

47 Shieh HF, Wilson JM, Sheils CA, et al. Does the ex utero intrapartum treatment to extracorporeal membrane oxygenation procedure change morbidity outcomes for high-risk congenital diaphragmatic hernia survivors? J Pediatr Surg 2017;52:22-5.

48 Stoffan AP, Wilson JM, Jennings RW, et al. Does the ex utero intrapartum treatment to extracorporeal membrane oxygenation procedure change outcomes for high-risk patients with congenital diaphragmatic hernia? J Pediatr Surg 2012;47:1053-7.

49 Wedgwood S, Steinhorn RH, Lakshminrusimha S. Optimal oxygenation and role of free radicals in PPHN. Free Radic Biol Med 2019.

50 Riley JS, Antiel RM, Rintoul NE, et al. Reduced oxygen concentration for the resuscitation of infants with congenital diaphragmatic hernia. J Perinatol 2018;38:834-43

51 Morini F, Capolupo I, van Weteringen W, et al. Ventilation modalities in infants with congenital diaphragmatic hernia. Semin Pediatr Surg 2017;26:159-65. 
52 Blank DA, Badurdeen S, Omar F Kamlin C, et al. Baby-directed umbilical cord clamping: a feasibility study. Resuscitation 2018;131:1-7.

53 Brouwer E, Knol R, Vernooij ASN, et al. Physiological-based cord clamping in preterm infants using a new purpose-built resuscitation table: a feasibility study. Arch Dis Child Fetal Neonatal Ed 2019;104:F396-402.

54 Polglase GR, Blank DA, Barton SK, et al. Physiologically based cord clamping stabilises cardiac output and reduces cerebrovascular injury in asphyxiated near-term lambs. Arch Dis Child Fetal Neonatal Ed 2018;103:F530-8.

55 Hooper SB, te Pas AB, Lang J, et al. Cardiovascular transition at birth: a physiological sequence. Pediatr Res 2015;77:608-14.
56 Lakshminrusimha S, Vali P. Congenital diaphragmatic hernia: 25 years of shared knowledge; what about survival? J Pediatr 2019. doi:10.1016/j.jped.2019.10.002. [Epub ahead of print: 17 Oct 2019].

72 Foglia EE, Ades A, Hedrick HL, et al. Initiating resuscitation before umbilical cord clamping in infants with congenital diaphragmatic hernia: a pilot feasibility trial. Arch Dis Child Fetal Neonatal Ed 2020;105:F322-6.

$58 \mathrm{Knol}$ R, Brouwer E, van den Akker T, et al. Physiological-based cord clamping in very preterm infants - randomised controlled trial on effectiveness of stabilisation. Resuscitation 2020;147:26-33. 